\title{
Comparative Study on the Patent Maintenance Fees System of Countries or Areas in Asia
}

\author{
Yongzhong Qiao ${ }^{1,}$, , Jiajia Gao ${ }^{1, b}$ \\ ${ }^{1}$ Intellectual Property Research Institute, Xiamen University No. 422, Siming South Road, Xiamen, \\ Fujian, China \\ agyzhl@163.coml, ’574602258@qq.com
}

\begin{abstract}
Keywords: patent; maintenance fee; country; area
Abstract. Comprehensively analyzed the patent laws in 18 Asian countries or areas, studied on the incentive mechanism of the patent maintenance fees system, then put forward some suggestions based on the patent maintenance fees system and the charging standard: The down payment on maintenance fees is of more practical value from the third to sixth year after the filing date of the application; The charging standard with an overall growing trend is more reasonable; The incomplete year-on-year growth model with the same amount during a few years is theoretically more advantageous.
\end{abstract}

\section{Introduction}

Patents, as a form of IP protection, constitute a mechanism that aims to facilitate innovation and the commercialization of technologies, and the incentive effect on them will be impacted directly by the adaptation degree of the patent maintenance fees system to the legal and economic system at a certain stage [1,2]. Patents evolved as a way for an inventor to deny others the right to take advantage of their invention, by denying them the right to manufacture the invention or to license it. [3]And the maintenance fee is a must payment for the patent owner in order to maintain the validity of the patent, and it shall be paid to the Administrative Department in accordance with the stipulated time and amount, however, due to the differences in the legal system, the economic development and so on, the patent maintenance fees systems are diversified among countries.

The patent maintenance fees system plays an important role in the technological innovation. Not a lot researches were conducted worldwide, and most of them are about the patent system in European. [4] The patent maintenance fees system in EU takes the incomplete year-on-year growth model with the same amount during a few years ${ }^{\mathbb{1}}$ which fits to some of the arguments put forward by the economic literature on maintenance fees, and follows an exponential trend to ensure an effective endogenous correction mechanism. As the study of Harhoff and Wagner shown, from 1982 to 1988 the average granted time of EPO is 4.2 years. [5] The newest study on granted time showed $66.5 \%$ patents get granted from the fourth to sixth year after the filing date of the application [6]. These studies are important for the discussion of the patent maintenance fees system in European, but researches on Asia especially the patent maintenance fees system in China are less [7]. According to 2014 China effective patent annual report in November 2015, the effective maintenance time of domestic patent owners granted by China was almost concentrated in 3-6 years, far less than its statutory protection term. The result was affected by various factors, among which the patent maintenance fees system influenced the maintenance time to a great extent from the aspect of the cost [8]. Thus it's necessary to study on the patent maintenance fees system.

Improving the patent maintenance fees system is of great theoretical value and practical significance to promote the implementation of Innovation Driven Development Strategy and construction of the Powerful Country in Intellectual Property. By comparing the patent maintenance fees systems in 18 Asian countries or areas, such as the maintenance fee amount, the down payment and so on, the promotional impact of different models on technological innovation development was discussed.

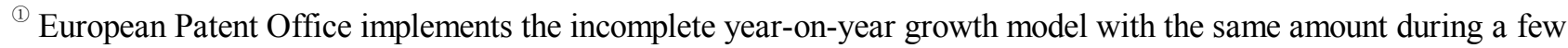
years, in which the patent owner must pay maintenance fee yearly, after the tenth year the amount remains the same, while in the other years, it gradually increases.
} 
Through comprehensively analyzing the charging standards in different countries, exploring the incentive mechanism of the patent maintenance fees system, we can summarize the factors that promote technological innovation in order to advice on the patent maintenance fees system.

\section{Date Sources}

In this paper, the maintenance fee information of 18 Asian countries or areas ${ }^{2}$ is conducted from their Intellectual Property Offices or Patent Office Web sites. In these sites, we select "patent", "maintenance fee", "maintenance fee and form" and other key words in related pages to get the information of maintenance fees. Due to inconsistent monetary units in the collected original data, and to be compared conveniently, the article converts it into RMB unit uniformly based on exchange rates from Watergate database in 16:00 September 30, 2016.

\section{Comparative Analysis of the Patent Maintenance Fees System in Asian Countries or Areas}

The maintenance fees in 18 Asian countries or areas are shown as Fig. 1, which includes China, China Hong Kong, Korea, Japan, Laos, Cambodia, Malaysia and so on. The maintenance fees in each country or area vary greatly because of their differences in the economic development, the social system, the scientific research innovation level and other factors. Only the maintenance fees in Malaysia are from the date of granted, and the remaining 17 countries or areas are from the filing date of the application.

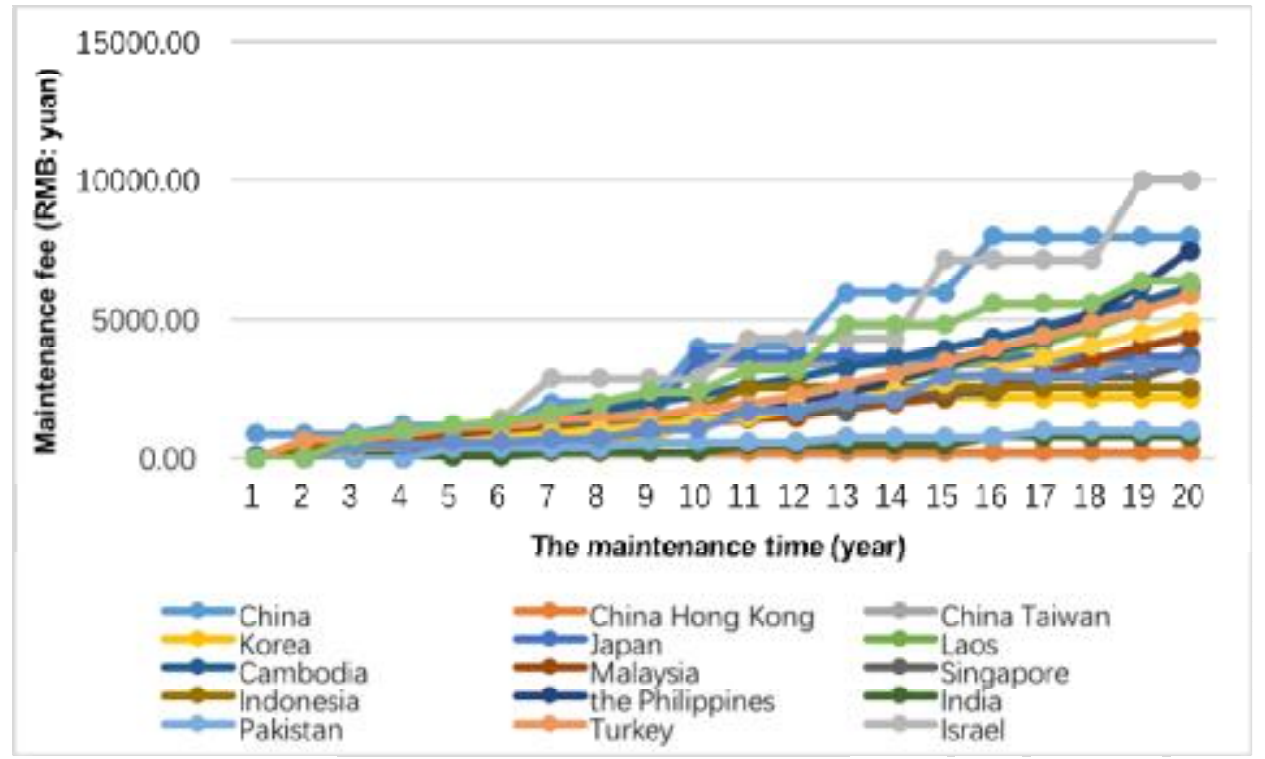

Fig. 1 The comparison of the patent maintenance fees systems in 18 Asia countries or areas

As it's shown in Fig. 1, there are six characteristics: first, all the maintenance fees in 18 countries or areas have an overall growing trend. Second, the start time to pay maintenance fees is different. Since the first year from the filing date of the application to pay it, there are 3 countries and they are China, Japan and Korea; since the second year from the filing date of the application or the date of granted, there are China Taiwan, Laos, Malaysia, Indonesia and Turkey; since the third year from the filing date of the application, there are 4 countries including India, Cyprus, Tajikistan and Kyrgyzstan; China Hong Kong begins to pay maintenance fees since the fourth year from the filing date of the application; Since the fifth year from the filing date of the application, Cambodia, Singapore, the Philippines and Pakistan need to pay maintenance fees; Israel needs to pay a maintenance fee in the

\footnotetext{
${ }^{2}$ Because the limitation of maintenance fee information was disclosed by intellectual property office of each country or area and the retrieval methods, our research group only found the maintenance fee data in 18 countries or areas.
} 
first six years from the filing date of the application. So the time distribution is balanced. Third, the growth rate of maintenance fees is different. In the first six years the maintenance fees in 18 countries or areas increase relatively slowly, then the maintenance fees in Israel increase the most, followed by China. Fourth, the maintenance fee amount is different. In the first six years there is no significant difference among the maintenance fees in 18 countries or areas, then the maintenance fees in China and Israel increase faster. Sixth, the maintenance fees in 18 countries or areas display four models. 11 countries or areas implement the step-growth model such as China, China Hong Kong, China Taiwan, Korea, Japan, Singapore, Indonesia, India, Pakistan, Tajikistan and Kyrgyzstan; there are 5 countries carrying out the year-on-year growth model including Cambodia, Malaysia, the Philippines, Turkey and Cyprus; Laos implements the incomplete year-on-year growth model with the same amount during a few years; Israel carries out the step-growth model with charging a maintenance fee in the first six years.

With all the said, the start time to pay maintenance fees is a more balanced distribution. Meanwhile, in the first six years the maintenance fees in 18 countries or areas increase relatively slowly, which is helpful for the patent owners to find their way to maximize their income. Most Asian countries carry out the step-growth model with a certain stability.

\section{The Comparison of the Step-growth Models of Maintenance Fee}

The step-growth model of maintenance fee is the payment model that the patent owner must pay maintenance fees every year, and the maintenance fee amount isn't increase yearly but every few years, and during the other years the amount remains the same. 11 countries or areas implement the step-growth model including China, China Hong Kong, China Taiwan, Korea, Japan, Singapore, Indonesia, India, Pakistan, Tajikistan and Kyrgyzstan, whose patent maintenance fees are shown as Fig. 2.

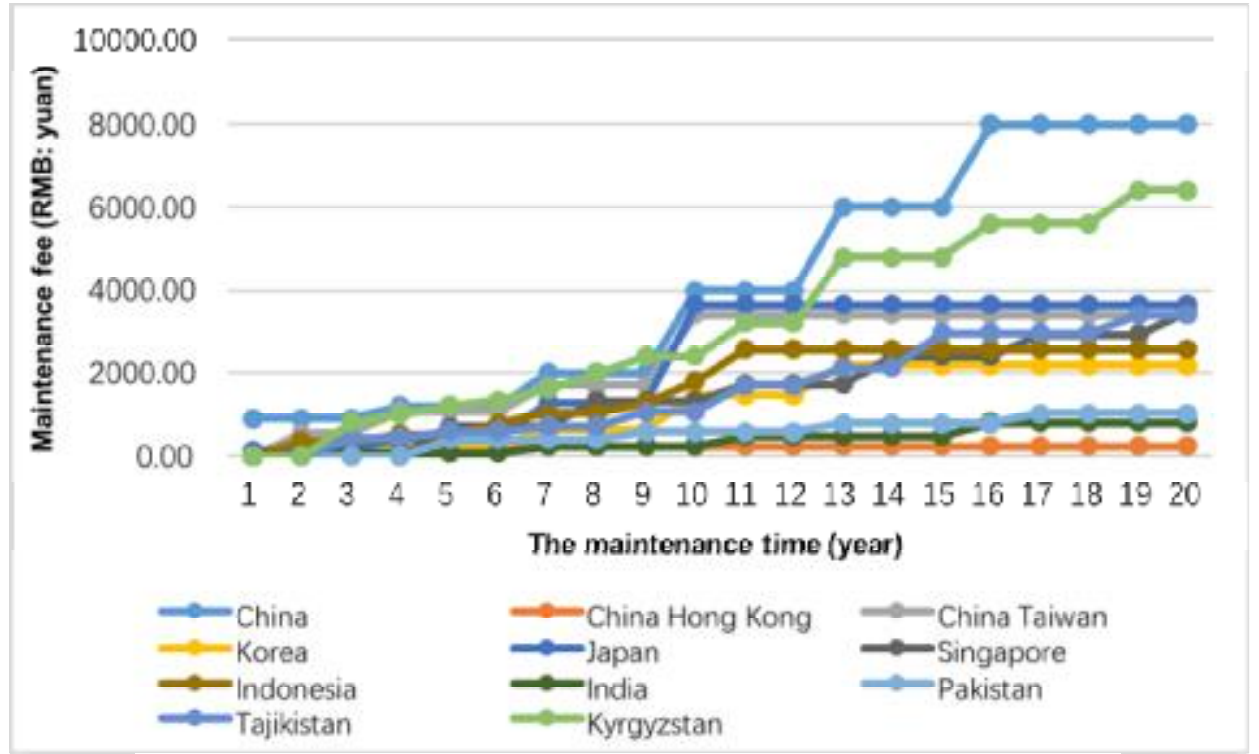

Fig. 2 The comparison of the step-growth models of maintenance fee

As it's shown in Fig. 2, the step-growth models of maintenance fee in Asian countries have the following characteristics: first, all the start time of the patent maintenance fees systems in 11 countries or areas is from the filing date of the application. Second, the start time to pay maintenance fees is different, and its distribution is balanced. Third, all the maintenance fees in 11 countries or areas have a growing trend, but the growth nodes and the growth rate have great differences. Fourth, the maintenance fee amount for each node varies. In the first four years the maintenance fees in China are the highest; in the fifth to ninth year the maintenance fees in China and Kyrgyzstan are higher than others alternately; after the tenth year the maintenance fees in China are the highest, followed by 
Kyrgyzstan, and the lowest is China Hong Kong. Fifth, different countries have different growth rates in the growth nodes. In the first nine years the maintenance fees in 11 countries or areas increase relatively slowly, then the growth rate of maintenance fees in China achieves the maximum, followed by Kyrgyzstan, and the lowest is China Hong Kong. To sum up, the maintenance fee amount in China is higher and the growth rate is larger among these countries or areas.

With all the said, the step-growth models in the 11 Asian countries or areas are implemented differently. First, in the first nine years the country or area with the highest maintenance fee changes frequently, and after that the maintenance fees in China are the highest; next, the growth nodes distribution varies greatly; finally, the growth rate in different countries exhibits large difference.

\section{The Comparison of the Year-on-year Growth Models of Maintenance Fee}

The year-on-year growth model of maintenance fee is the payment model that the patent owner must pay maintenance fees yearly and the charging standard increases year by year. There are five countries that implement the year-on-year growth model, including Cambodia, Malaysia, the Philippines, Turkey and Cyprus. The maintenance fees are shown as Fig. 3.

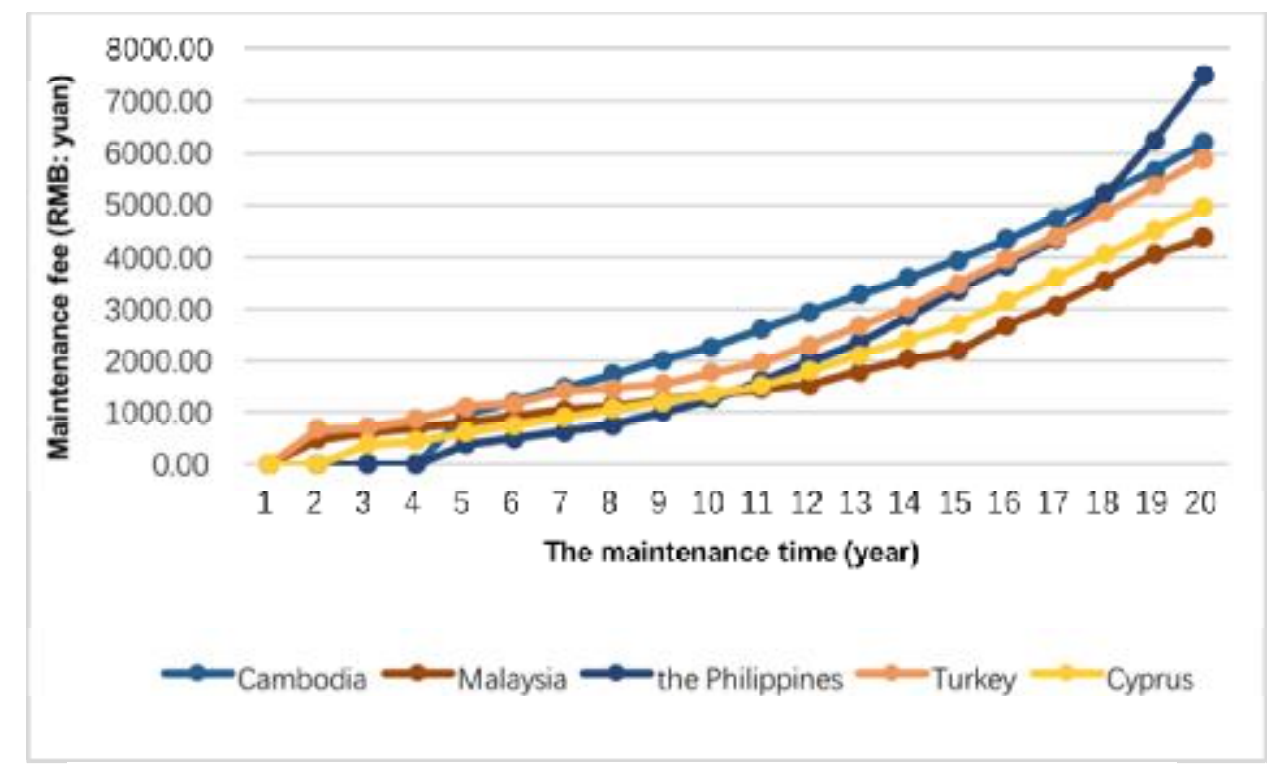

Fig. 3 The comparison of the year-on-year growth models of maintenance fee

As can be seen from Fig. 3, the year-on-year growth model of maintenance fee has the following five characteristics: First, the start time of the patent maintenance fees systems is different. The maintenance fees in Malaysia are from the date of granted, the remaining countries are from the filing date of the application. Second, the start time to pay maintenance fees is different. In Malaysia and Turkey, the maintenance fees are paid since the second year from the filing date of the application or the date of granted, Cyprus is the country starting to pay maintenance fees since the third year from the filing date of the application; Since the fifth year from the filing date of the application, Cambodia and the Philippines need to pay maintenance fees. Third, all the maintenance fees in 5 countries have an overall growing trend, but their growth rates and the maintenance fee amount differ from each other. Fourth, the growth rate is different. In the first four years the maintenance fees in Turkey increase the fastest, followed by Malaysia, while Cyprus is the slowest. In the fifth to thirteenth year the maintenance fees in Cambodia increase the fastest; in the fourteenth to twentieth year the growth rate of maintenance fees in the Philippines is the highest. Fifth, the maintenance fee amount in 5 countries is different. In the first five years the maintenance fees in Turkey are the maximum; in the sixth to seventeenth year the maintenance fee amount in Cambodia is the largest, followed by Turkey; in the eighteenth to twentieth year the maintenance fee amount in the Philippines is the largest. 
To sum up, the patent maintenance fees systems in 5 countries implementing the year-on-year growth model differ from each other. And the growth model in the Philippine is more special, starting to pay maintenance fees since the fifth year from the filing date of the application, in the first ten years having the lowest maintenance fees, and its amount exceeds the rest of the countries successively with the growth rate increasing.

\section{Analysis of the Incomplete Year-on-year Growth Model with the Same Amount during a Few Years of Maintenance Fee}

The incomplete year-on-year growth model with the same amount during a few years is the payment model that the patent owner must pay maintenance fees yearly, but it remains the same during a few years occasionally, and in the other years the amount increases gradually. It's shown as Fig. 4.

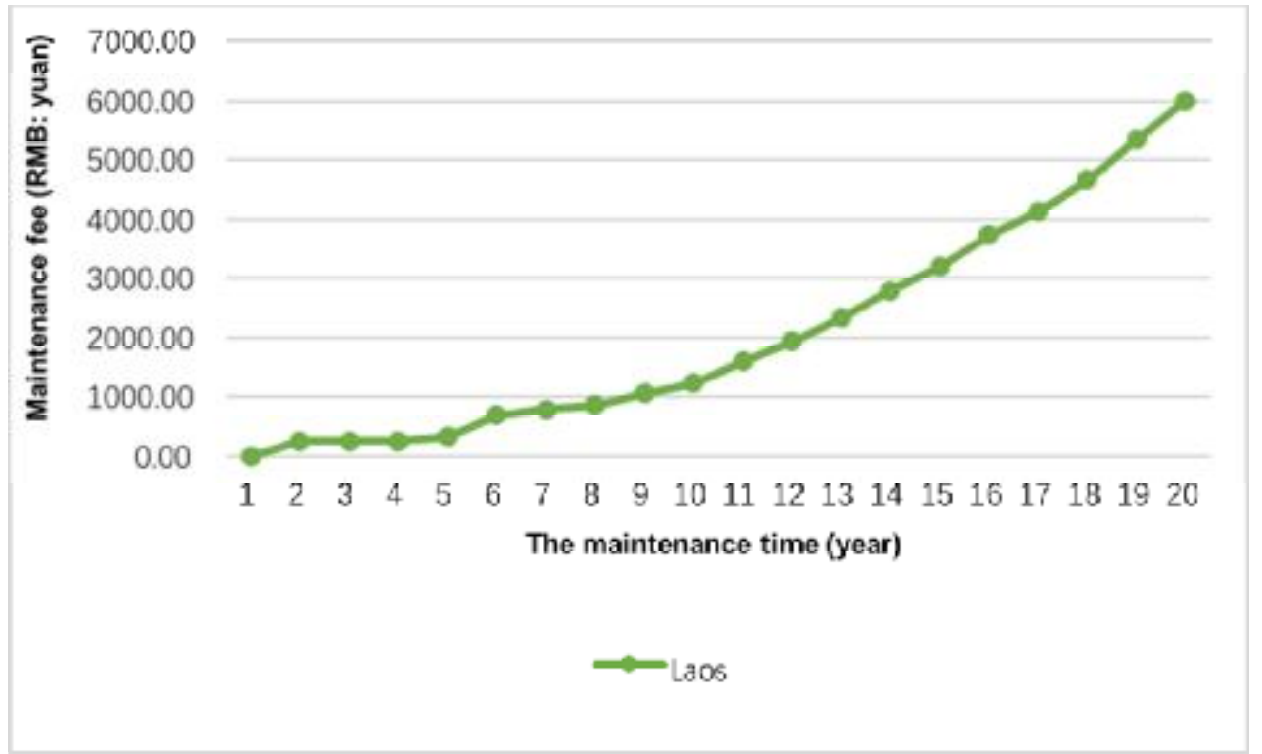

Fig. 4 Analysis of the incomplete year-on-year growth model with the same amount during a few years of maintenance fee

It's shown as Fig. 4, that the patent maintenance fees system in Laos has the following four characteristics: First, the patent maintenance fees system in Laos is from the filing date of the application. Second, Laos starts to pay maintenance fees since the second year from the filing date of the application. Third, the maintenance fees in Laos have an overall growing trend. Fourth, the maintenance fee amount in Laos remains the same from the second to the fourth year, and increases gradually in the other years.

Above all, the incomplete year-on-year model with the same amount during a few years taken by Laos exhibits flexibility like the year-on-year growth model, and has stability and acceptability like the step-growth model. Patent income increases with the granted time increasing, and the year-on-year growth model is more in line with the actual situation. Keeping the maintenance fee amount the same during the early stage helps the patent owner to accept and pay maintenance fees. There is more significance compared to the step-growth model and the year-on-year growth model.

\section{Analysis of the Step-growth Model with Charging a Maintenance fee in the First Six Years}

The step-growth model with charging a maintenance fee in the first six years is the payment model that the patent owner only needs to pay a maintenance fee in the first six years, and in the other years must pay maintenance fees annually which doesn't increase year by year, but every few years, with the left years unchanged. Israel implements the step-growth model with charging a maintenance fee in the first six years, and its maintenance fees are shown as Fig. 5. 


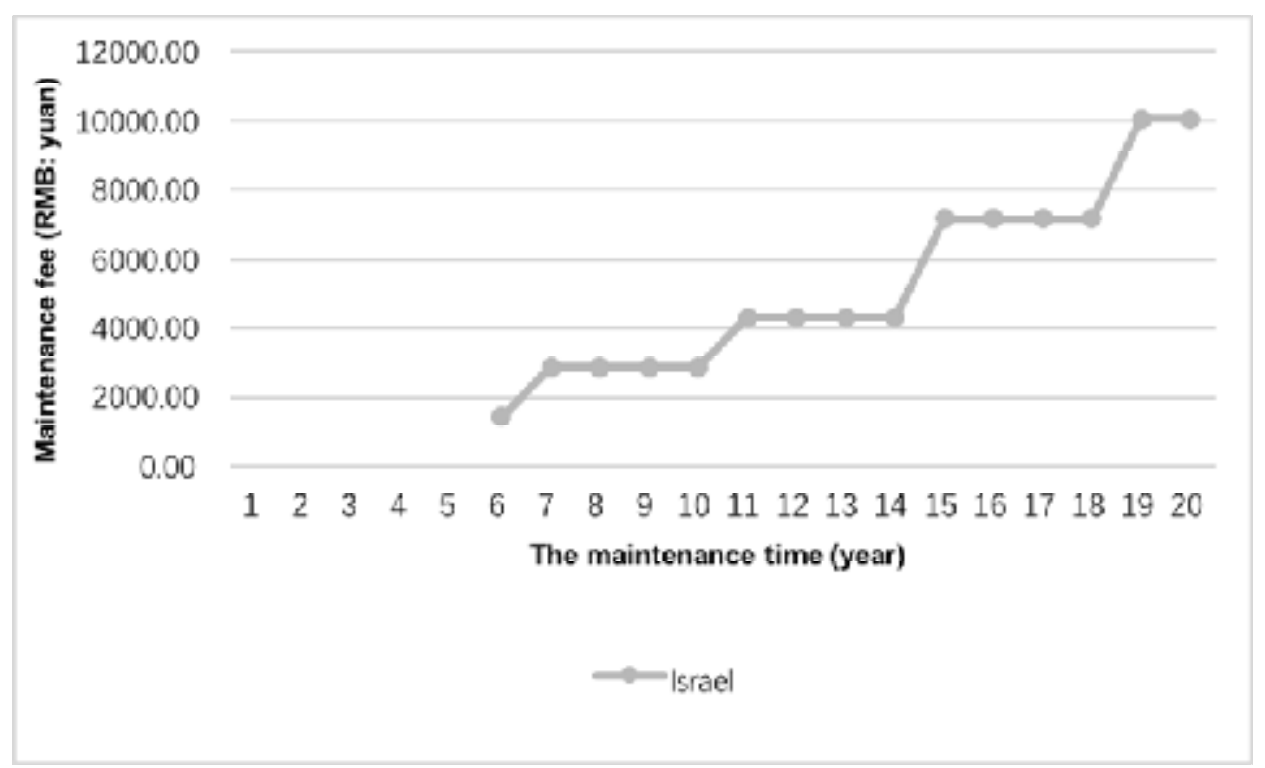

Fig. 5 Analysis of the step-growth model with charging a maintenance fee in the first six years

As it's shown in Fig. 5, the step-growth model with charging a maintenance fee in the first six years has the following four characteristics: First, the patent maintenance fees system in Israel is from the filing date of the application. Second, the growth nodes of the patent maintenance fees system in Israel have a certain regularity. The maintenance fees increase by a certain level every 4 years since the seventh year from the filing date of the application. Third, the growth rate in Israel varies. The growth rate of the sixth year to seventh year is similar to the rate of the tenth to eleventh year; the growth rate of the fifteenth year to the sixteenth year is similar to the rate of the eighteenth to nineteenth year, and it is greater than the previous two.

To sum up, the patent maintenance fees system in Israel simplifies payment procedures, bringing convenience to the patent owner in a certain extent, meanwhile it is stiff, and the mandatory requirement for the term of patent protection cannot be less than six years. Although it simplifies the payment procedure, it cannot reflect the actual situation that the patent income increases with the granted time, and the later growth rates are larger than the rate in previous stage, which facilitates the earlier entering of related technology into the public domain.

\section{Conclusions}

The patent maintenance fees system reflects the level that the patent owner weighs benefit and cost to effectively select the length of the protection term of intellectual property rights in a specific country at a specific time. The policymakers should be aware that the system can promote technology trade and innovation to some extent, and learn to manipulate the "strength" of their invention patent regimes. $[9,10]$ To sum up, four points can be concluded: First, due to their different specific legal, economic, historical and the other factors, the countries exists a maintenance fee charging standard which is beneficial to the development of its patent system, although the standard for the country or area isn't optimal, or it's optimal at this moment but not in the future. Second, most countries or areas set the charging standard according to the course of the profit from patent. There are some differences among their patent maintenance fee models, but on the whole, they present an overall growing trend. Third, the down payment of Asian countries or areas on maintenance fees has a balanced distribution; the countries which pay maintenance fees after the third year ${ }^{3}$ from the filing date of the application are relatively more ${ }^{(4)}$. From reality, considering that it takes 3-4 years for the general patent application to get granted, the institutional arrangement is reasonable. Fourth, there are various patent maintenance

\footnotetext{
${ }^{3}$ After the third year include the third year, the fourth year, the fifth year, the sixth year from the filing date of the application.

(4) There are eleven countries starting to pay maintenance fees after the third years.
} 
fee models, including the step-growth models, the year-on-year growth model, the incomplete year-on-year growth model with the same amount during a few years, and the step-growth model with charging a maintenance fee in the first six years. In the 18 Asian countries or areas, the step-growth model occupies the largest percentage. After analyzing maintenance fees in different areas, there are some suggestions on the patent maintenance fees system and its charging standard. Firstly, the start time to pay maintenance fees after three years from the filing date of the application is more reasonable, because it will take three to four years for the general patent application to get granted. Secondly, the patent maintenance fees system should present a growing trend. Such an arrangement will help the patent to enter into the public domain earlier, but at the same time, the interests of the patent owner should be taken into account. The maintenance fee amount needs to be further explored in the light of the specific economic and legal circumstances of the country or area. At last, according to the patent maintenance fees models, theoretically the incomplete year-on-year growth model with the same amount during a few years is more reasonable, and it has some reference significance for the patent maintenance fees models in all countries.

\section{Acknowledgements}

This paper is funded by National Natural Science Foundation of China (NSFC) Project "Empirical study on the maintaining mechanism and regularity of patent" (71373221).

\section{References}

[1] K. Raiser, H. Naims and T. Bruhn. Corporatization of the climate? Innovation, intellectual property rights, and patents for climate change mitigation: Energy Research \& Social Science Vol. 27 (2017), p. 1-8

[2] Yongzhong Qiao. Comparative analysis of the patent maintenance fees system between Us, Japan, Europe and China: Electronic intellectual property Vol. Z1(2011), p. 130-134 (in Chinese)

[3] Gail A. Van Norman, Roï Eisenkot. Technology Transfer: From the Research Bench to Commercialization: Part 1: Intellectual Property Rights-Basics of Patents and Copyrights: JACC: Basic to Translational Science Vol. 2(2017), p. 85-97

[4] Danguy J, Potterie B V P D L. Patent fees for a sustainable EU patent system: World Patent Information Vol. 33(2011), p. 240-247

[5] Harhoff D, Wagner S. The Duration of Patent Examination at the European Patent Office: Journal of Cancer Research and Clinical Oncology Vol. 71(1968), p. 59-62

[6] Harhoff D, Hoisl K, Reichl B. Patent validation at the country level-The role of fees and translation costs: Social Science Electronic Publishing Vol. 38(2009), p. 1423-1437

[7] Lanjouw J O. Patent Protection in the Shadow of Infringement: Simulation Estimations of Patent Value: Review of Economic Studies Vol. 65(1998), p. 671-710

[8] Yongzhong Qiao. study on the influencing factors of patent maintenance time: Scientific Research Management Vol. 32(2011), p. 143-149 (in Chinese)

[9] Rassenfosse G D, Palangkaraya A and Webster E. Why do patents facilitate trade in technology? Testing the disclosure and appropriation effects: Research Policy Vol. 45(2016), p. 1326-1336

[10] Dan P. Utility model patent regime "strength" and technological development: Experiences of China and other East Asian latecomers: China Economic Review Vol. 42(2017), p. 50-73 